ISSN = 1980-993X - doi:10.4136/1980-993X
www.ambi-agua.net
E-mail: ambi-agua@agro.unitau.br
Tel.: (12) 3625-4212

\title{
Qualidade da água de chuva armazenada em cisterna utilizada na dessedentação de suínos e bovinos de corte
}

\author{
(http://dx.doi.org/10.4136/ambi-agua.822) \\ Julio Cesar Pascale Palhares ${ }^{1}$; Antônio Lourenço Guidoni ${ }^{2}$ \\ ${ }^{1}$ Embrapa Pecuária Sudeste, São Carlos, São Paulo, Brasil \\ ${ }^{2}$ Embrapa Clima Temperado, Pelotas, Rio Grande do Sul, Brasil \\ e-mails: palhares@cppse.embrapa.br; antlogui@gmail.com
}

\section{RESUMO}

Na região do Meio Oeste Catarinense tem-se incentivado a utilização de cisternas como tecnologia capaz de ofertar água aos rebanhos. A região é caracterizada por secas severas nos meses de verão. Os objetivos da pesquisa foram: monitorar variáveis físicas, químicas e microbiológicas de qualidade da água de chuva de uma cisterna; avaliar se a água armazenada possuía qualidade para dessedentação de suínos e bovinos de corte. As concentrações de nitrato, nitrito e amônia mantiveram-se de acordo com os padrões para o consumo animal. A E. coli esteve presente em algumas amostras. A quantidade de chuva e velocidade do vento influenciaram as concentrações dos elementos nitrogenados. Investigações a fim de aprofundar esse conhecimento devem ser conduzidas para que as fontes emissoras agrícolas e pecuárias não representam alto impacto negativo para a qualidade da água. A água armazenada na cisterna apresentou qualidade satisfatória para o uso na dessedentação de suínos e bovinos de corte o que corrobora a utilização da tecnologia, visando o uso eficiente da água pelas produções pecuárias.

Palavras-chave: coliformes; legislação; nitrato; nitrogênio amoniacal.

\section{Rain water quality of a cistern used for pigs and beef cattle}

\begin{abstract}
Santa Catarina State has encouraged the use of cisterns as a technology to offer water in quantity and quality to livestock. The region is characterized by severe droughts in the summer months. The aims of the study were: to monitor physical, chemical and microbiological rain water quality parameters of a cistern; to evaluate if water had quality for pigs and beef cattle water consumption. Concentrations of nitrate, nitrite and ammonia were in accordance with the standards for animal consumption. E. coli was present in some samples. The rainfall and speed of wind influenced the concentrations of nitrogen. Investigations of the relations between these environmental parameters and water quality must be conducted to avoid agricultural and livestock emission sources to have a negative impact on water quality. The water stored in the cistern showed satisfactory quality for use of pigs and beef cattle drinking. This gives support to the utilization of this technology to improve the water use efficiency for livestock.
\end{abstract}

Keywords: ammonium nitrogen; coliforms; legislation; nitrate. 
PALHARES, J. C. P.; GUIDONI, A. L. Qualidade da água de chuva armazenada em cisterna utilizada na dessedentação de suínos e bovinos de corte. Ambi-Agua, Taubaté, v. 7, n. 1, p. 244-254, 2012. (http://dx.doi.org/10.4136/ambi-agua.822)

\section{INTRODUÇÃO}

A disponibilidade de água em quantidade e qualidade para os rebanhos é uma preocupação dos produtores rurais devido às constantes ameaças antrópicas a esse recurso natural. Essas ameaças são intensificadas em regiões nas quais a concentração de animais por unidade de área é elevada, a ocorrência de secas é um fator inerente aos ciclos produtivos, há conflitos pelo uso da água e o atendimento ao saneamento urbano e rural são precários.

O uso de cisterna para o armazenamento de água da chuva é uma tecnologia que pode atenuar as ameaças citadas bem como dispor água para os rebanhos. Essa tecnologia tem sido utilizada desde as primeiras organizações humanas e seu uso é fomentado por governos e instituições ao redor do mundo, principalmente, nas regiões onde a disponibilidade de água é escassa em quantidade e qualidade. A captação da água da chuva e seu armazenamento em cisternas, além de promover a segurança hídrica, promovem a segurança alimentar e econômica de produtores rurais e territórios.

O armazenamento de água da chuva é prática comum em muitas nações há milhares de anos, especialmente nas zonas áridas ou remotas, onde o fornecimento de água encanada ou através de redes não é rentável ou tecnicamente viável (Simmons et al., 2001; Ngigi, 2003; Prado et al., 2007). A colheita de água da chuva inclui todas as etapas relacionadas a captação, armazenamento, utilização e gestão da água para finalidades produtivas (agricultura, pastagem, silvicultura, pecuária e abastecimento de água doméstica, etc.). Os componentes de um sistema de aproveitamento de água pluvial variam de acordo com o uso que se pretende fazer, da qualidade da água desejada, do espaço para as instalações e dos recursos financeiros disponíveis (Mantovan et al., 1995).

Estudos relacionando o armazenamento de água em cisternas com as variáveis físicas, químicas e microbiológicas da água são escassos, bem como programas de monitoramento a fim de estabelecer relações entre as condições climáticas e de captação e armazenamento com as exigências qualitativas dos diversos usos.

Há uma ausência de informações científicas quanto à qualidade da água coletada dos telhados, com isso tem-se assumido que está é uma fonte relativamente segura, até mesmo para o consumo humano (Lye, 2009).

O tipo de uso que se pretende fazer da água irá determinar à qualidade que essa deve ter e consequentemente a gestão da tecnologia. A utilização da água de cisterna para dessedentação de animais é um uso nobre. O referencial de qualidade para esse tipo de uso são as Resoluções 357 (Brasil, 2005) e 396 (Brasil, 2008) do CONAMA. Também deve ser considerada a ABNT NBR 15527 (ABNT, 2007).

A qualidade da água da chuva captada em cisternas depende da pureza da atmosfera e do entorno desta, da época do ano, da duração e intensidade da chuva, das condições regionais, dos materiais usados para construir a área de captação, das impurezas depositadas na superfície do telhado, das calhas que conduzem a água para a cisterna, da "ecologia da cisterna", da maneira como se tira a água, do contato humano e do tipo de tratamento antes do consumo .

Normalmente a qualidade química e física de água de chuva armazenada nas cisternas é boa, mas é difícil atingir, sem cuidados específicos, um padrão de qualidade com ausência de coliformes (Brito e Gnadlinger, 2006). A água da chuva é naturalmente livre de organismos patogênicos, mas pode tornar-se contaminada devido ao contato com as superfícies de captação e armazenamento. Portanto, a qualidade microbiológica da água irá depender das condições de armazenamento, fatores como temperatura e tempo, manutenção e práticas sanitárias relacionadas ao sistema (WHO, 2008). A coleta de água da chuva insere potenciais riscos a saúde devido à presença de possíveis contaminantes microbiológicos e químicos. Patógenos podem ter origem fecal de aves, mamíferos e répteis que têm acesso as áreas de 
PALHARES, J. C. P.; GUIDONI, A. L. Qualidade da água de chuva armazenada em cisterna utilizada na dessedentação de suínos e bovinos de corte. Ambi-Agua, Taubaté, v. 7, n. 1, p. 244-254, 2012. (http://dx.doi.org/10.4136/ambi-agua.822)

captação ou armazenamento. A contaminação química pode ocorrer devido às emissões do tráfego e da poluição industrial em áreas urbanas ou devido ao uso agrícola de adubos e pesticidas nas áreas rurais (Sazaklia, 2007).

A região do Meio Oeste Catarinense é uma tradicional produtora de suínos, aves de corte e bovinos de leite, sendo historicamente caracterizada por uma das maiores concentrações de animais do país. A região também apresenta um período de severa estiagem na época do verão o que tem condicionado perdas agrícolas e dos rebanhos por falta de água. Esse cenário tem sido utilizado como motivador para implantação de cisternas nas propriedades rurais a fim de reduzir o impacto da estiagem, principalmente, quanto à oferta de água para os animais. A literatura indica a possibilidade do uso dessa água para a dessedentação de animais, mas não há pesquisas no país que tenham como foco essa avaliação.

A validação do uso de água de chuva armazenada em cisternas para a dessedentação de animais pode promover a segurança hídrica das propriedades rurais em três dimensões: ambiental, conservando o recurso natural devido à menor extração das fontes superficiais e subterrâneas, promovendo o uso racional da água e consequentemente maior eficiência hídrica das produções, reduzindo a pegada hídrica das criações; social, auxiliando na manutenção do homem no campo por contribuir para a independência hídrica da propriedade e reduzir sua dependência a fontes externas, promovendo o bem estar de humanos e animais, facilitando o cumprimento da legislação ambiental; econômica, reduzindo o impacto do custo da água no custo de produção das atividades.

A pesquisa constituísse em um estudo de caso de caráter descritivo no qual o pesquisador não interveio no manejo da tecnologia e apresentou os seguintes objetivos: monitorar variáveis físicas, químicas e microbiológicas de qualidade da água de uma cisterna que armazena água de chuva; avaliar se a água armazenada possuía qualidade para dessedentação de suínos e bovinos de corte.

\section{MATERIAL E MÉTODOS}

O estudo de caso foi conduzido entre os meses de novembro de 2008 a maio de 2010 em propriedade rural localizada no município de Concórdia, Santa Catarina, Brasil. As coordenadas geográficas são: latitude $-27.270075^{\circ}$ e longitude $-51.960881^{\circ}$. A propriedade situa-se a uma altitude de $691 \mathrm{~m}$.

$\mathrm{O}$ clima do município é temperado, com temperaturas médias de $17,9^{\circ} \mathrm{C}$ a $19,8^{\circ} \mathrm{C}$, máximas variando de $25,8^{\circ} \mathrm{C}$ a $27,5^{\circ} \mathrm{C}$ e mínimas de $12,9^{\circ} \mathrm{C}$ a $14,0^{\circ} \mathrm{C}$. A precipitação anual varia entre $1.430 \mathrm{~mm}$ e $2.020 \mathrm{~mm}$, com dias de chuva que variam de 108 a 150 dias.

A propriedade denominada como de agricultura familiar, apresentava o perfil produtivo, econômico e social típico das propriedades rurais localizadas nas regiões do Meio-Oeste e Oeste de Santa Catarina. A área total era de 34 ha, 22 ha eram ocupados com culturas (milho, 16 ha; pastagem, 5 ha; uva, 0,5 ha; erva-mate, 0,5 ha) e 7 ha com mata nativa. As atividades comercialmente desenvolvidas eram a suinocultura (610 animais em terminação); bovinocultura de corte (seis vacas e 39 bezerros); milho; uva.

Como principais características sociais da propriedade destacam-se: possuía uma unidade residencial com quatro adultos e uma criança; os adultos tinham baixo nível de escolaridade (três adultos não possuíam o ensino fundamental completo e um possui até a primeira série do ensino médio), havia contratação de mão-de-obra temporária nos momentos de intensificação das atividades agrícolas.

Quanto às condições ambientais, na propriedade existia uma fonte permanente de água que era utilizada para consumo humano e animal; a fonte estava protegida de acordo com as exigências da legislação ambiental; possuía licença ambiental somente para atividade 
PALHARES, J. C. P.; GUIDONI, A. L. Qualidade da água de chuva armazenada em cisterna utilizada na dessedentação de suínos e bovinos de corte. Ambi-Agua, Taubaté, v. 7, n. 1, p. 244-254, 2012. (http://dx.doi.org/10.4136/ambi-agua.822)

suinícola; os dejetos animais eram utilizados como fertilizantes em todas as áreas sem orientação técnica.

A cisterna foi construída em agosto de 2008 devido aos recorrentes eventos de falta de água na estação da seca o que obrigava o proprietário adquirir de duas a quatro cargas de água por dia $(8.000 \mathrm{~L} /$ carga) para dessedentação dos animais. A cisterna estava localizada a $150 \mathrm{~m}$ de uma rodovia federal que apresentava intenso tráfego de veículos pesados.

O sistema foi dimensionado pelos técnicos da Prefeitura Municipal. A cisterna era escavada revestida com manta de polietileno e coberta com estrutura metálica e lona, evitando assim a entrada de insetos e sujeira. A lona de cobertura tinha sua parte externa na cor azul e parte interna na cor preta.

A capacidade de armazenamento era de $500 \mathrm{~m}^{3}$. A captação da água era feita de dois telhados de instalações para suínos e bovinos, totalizando $621 \mathrm{~m}^{2}$ de superfície de captação, por sistema de calhas de alumínio que ficavam junto ao beiral destes. Canos de PVC conduziam a água até o sistema de filtragem. Em ambos os galpões as telhas eram de fibrocimento, sendo que as partes metálicas tinham contato com a água captada. Telhados e o interior da cisterna nunca foram lavados.

Antes da água captada nos telhados entrar na cisterna ela passava por um sistema de filtração em série composto por três filtros. Os filtros eram feitos de caixas d'água plástica com capacidade de $2.000 \mathrm{~L}$ e tinham como meio filtrante basalto e britas. O primeiro filtro possuía rocha tipo basalto, sendo que no segundo e terceiro havia brita tipo 2 . O descarte da água das primeiras chuvas era realizado, mas essa passava pelo sistema de filtragem antes do descarte, o que proporcionava a rápida saturação do meio filtrante, demandando lavagem das britas de forme frequente. Durante o período de monitoramento ocorreram duas lavagens do meio filtrante.

As águas das primeiras chuvas eram descartadas de acordo com a percepção dos proprietários. Eles relataram que em alguns eventos esse descarte não ocorria, pois a chuva se dava a noite ou eles não tinham disponibilidade para fazer no momento necessário. A captação da água da cisterna era feita superficialmente e não havia sistema de cloração.

$\mathrm{O}$ monitoramento ocorreu com periodicidade mensal. As coletas para análise da qualidade da água ocorreram em dois pontos de amostragem, superfície da cisterna (coletas realizadas $20 \mathrm{~cm}$ abaixo da superfície da água) e fundo. As coletas para análise dos elementos nitrogenados (nitrato, nitrito e amônia) ocorreram somente na superfície.

No momento das coletas utilizou-se Sonda Multiparâmetro Modelo Hanna HI 9828 para monitorar a temperatura $\left({ }^{\circ} \mathrm{C}\right)$, oxigênio dissolvido $\left(\mathrm{mg} . \mathrm{L}^{-1}\right)$, potencial hidrogeniônico, potencial redox $(\mathrm{mV})$, Sólidos Dissolvidos Totais $(\mathrm{ppm})$ e condutividade elétrica $(\mu \mathrm{S} / \mathrm{cm})$.

Para cada ponto de amostragem foram coletados dois litros de amostra as quais eram acondicionadas em garrafas plásticas e armazenadas a $4^{\circ} \mathrm{C}$. Imediatamente após a coleta, as amostras eram levadas para o Laboratório de Análises Ambientais da Embrapa Suínos e Aves para determinação de nitrato $\left(\mathrm{N}-\mathrm{NO}_{3}\right)$, nitrito $\left(\mathrm{N}-\mathrm{NO}_{2}\right)$ e nitrogênio amoniacal $\left(\mathrm{N}_{-} \mathrm{NH}_{3}\right)$. O protocolo de amostragem, estabilização da amostra e análise estavam de acordo com os procedimentos da American Public Health Association (1995).

$\mathrm{Na}$ determinação do nitrito e do nitrato utilizou o método colorimétrico em um sistema de análise por injeção de fluxo. Foi utilizado um sistema multicanal FIAlab- 2500. Cabos de fibra ótica SMA $200 \mathrm{~mm}$ que ligam a célula de reação ao espectrofotômetro (Ocean-Optics S2000). Para determinação do nitrato foi utilizada coluna com $5 \mathrm{~g}$ de cádmio. A determinação do nitrogênio amoniacal foi realizada com eletrodo de íon seletivo da marca Thermo pelo método potenciométrico.

As análises microbiológicas foram realizadas no Centro de Diagnóstico de Sanidade Animal - Cedisa a partir de amostras de $200 \mathrm{~mL}$ coletadas em garrafas plásticas esterilizadas. 
PALHARES, J. C. P.; GUIDONI, A. L. Qualidade da água de chuva armazenada em cisterna utilizada na dessedentação de suínos e bovinos de corte. Ambi-Agua, Taubaté, v. 7, n. 1, p. 244-254, 2012. (http://dx.doi.org/10.4136/ambi-agua.822)

Analisou-se o número de Coliformes Totais (CT), Coliformes Termotolerantes (CF) e Escherichia coli $(\mathrm{Ec})$ em UFC $\mathrm{mL}^{-1}$ utilizando-se a metodologia de Placa Petrifilm.

O protocolo de amostragem para avaliação da qualidade da água também conteve: entrevista aberta com o produtor a fim de avaliar os eventos e manejos ocorridos no período anterior; relato dos resultados da amostragem do mês anterior; observação da cisterna e entorno.

As informações relacionadas a quantidade de chuva e a velocidade do vento foram geradas na Estação Meteorológica da Embrapa Suínos e Aves a qual faz parte da rede estadual de monitoramento meteorológico. A estação está localizada na unidade da Embrapa e a $5 \mathrm{~km}$ da propriedade de estudo.

O Brasil não dispõe de legislação ou normativa técnica que determine a qualidade que a água armazenada em cisterna deve ter para dessedentação de animais. Portanto, o referencial utilizado para verificar se a água da cisterna possuía qualidade para uso na dessedentação foi a Resolução Conama 357 que classifica as águas superficiais. A Resolução determina que águas superficiais destinada a esse uso deva cumprir os padrões Classe 3.

Por ser um estudo de caso, o trabalho gerou dados observacionais, portanto se enquadra na categoria dos delineamentos quase-experimentais em que as datas de amostragem são usadas como repetições no tempo e cada data é entendida como um fator aleatório do tipo bloco. Para fins de análise a condição de independência entre as datas é assumida e o modelo de análise é do tipo blocos (datas de amostragem) com dois tratamentos (profundidades da cisterna, superfície e fundo). Por se tratar de dados observacionais o nível de significância adotado chegou até a $15 \%$ de probabilidade. As comparações entre as profundidades foram feitas pelo Teste F. Calculou-se a correlação de Pearsosn entre cada variável de qualidade da água e as variáveis meteorológicas. As análises estatísticas foram realizadas com o programa SAS (2003).

\section{RESULTADOS E DISCUSSÃO}

$\mathrm{Na}$ discussão dos resultados irá se fazer a generalização analítica, ou seja, irá se generalizar a partir dos aspectos da unidade de estudo a qual pode ser caracterizada como representativa do modelo agrário familiar vigente no Estado e na região Sul do Brasil. Portanto, a validade externa da generalização foi estabelecida a partir das características socioeconômicas, produtivas e ambientais da propriedade o que garante a confiabilidade desse estudo de caso.

As maiores médias de chuvas concentraram-se entre agosto de 2009 e fevereiro de 2010 , o que corresponde às estações de primavera e verão. Neste período as médias de velocidade do vento também foram elevadas (Tabela 1). Chuva e vento são dois fatores que irão influenciar na qualidade da água armazenada na cisterna. $O$ vento carreará partículas em suspensão no ar, sendo que muitas destas irão ser depositadas na superfície de captação do telhado. Dependendo da orientação dos ventos e da posição das fontes emissoras, esse fator poderá depreciar a qualidade da água armazenada. Na região de estudo as maiores fontes de emissão de gases e partículas são a produção animal, potencial emissora de amônia e outros gases, e a agricultura, via manejo dos solos. A emissão de gases pelas produções animais é uma fonte de emissão constante, mas a contribuição da agricultura compreende um perfil sazonal, pois as maiores emissões ocorrerão no período de preparo da terra para o plantio e colheita do milho, entre os meses de julho e setembro e fevereiro, respectivamente.

Estudos demonstram a relação entre a composição química da água da chuva e a proximidade de fontes emissoras de poluição, padrões climáticos, transporte e disposição de partículas (Evans et al., 2007). Em regiões agrícolas as populações microbianas estão mais 
PALHARES, J. C. P.; GUIDONI, A. L. Qualidade da água de chuva armazenada em cisterna utilizada na dessedentação de suínos e bovinos de corte. Ambi-Agua, Taubaté, v. 7, n. 1, p. 244-254, 2012. (http://dx.doi.org/10.4136/ambi-agua.822)

presentes na atmosfera durante a época de colheita das culturas, há relatos de amostras de chuva com aspecto turvo nessas regiões durante esses meses (Agrios, 1997).

Tabela 1. Quantidade total de chuva, médias de chuva e velocidade do vento e valores mínimos e máximos entre o período de coletas.

\begin{tabular}{l|c|c|c|c}
\hline \multicolumn{1}{c|}{$\begin{array}{c}\text { Mês de } \\
\text { Coleta }\end{array}$} & $\begin{array}{c}\text { Dias } \\
\text { entre } \\
\text { coletas }\end{array}$ & $\begin{array}{c}\text { Total de chuva no } \\
\text { período entre as coletas } \\
\text { e valores mínimos e } \\
\text { máximos (mm) }\end{array}$ & $\begin{array}{c}\text { Média de Chuva } \\
\text { por dia (mm) }\end{array}$ & $\begin{array}{c}\text { Velocidade média do } \\
\text { vento por dia e valores } \\
\left.\text { mínimos e máximos (m.s } \mathbf{s}^{-1}\right)\end{array}$ \\
\hline novembro & - & - & - & - \\
dezembro & 21 & $60(8-20)$ & 2,8 & $1,70(1,7-2,3)$ \\
janeiro & 35 & $149(1-31)$ & 4,2 & $1,42(0,0-2,3)$ \\
fevereiro & 18 & $18(5-13)$ & 1,0 & $1,67(1,0-2,3)$ \\
março & 31 & $172(1-34)$ & 5,5 & $1,36(0,0-2,3)$ \\
abril & 32 & $41(1-22)$ & 1,3 & $1,45(1,0-2,5)$ \\
maio & 28 & $35(1-34)$ & 1,2 & $1,45(1,0-2,0)$ \\
junho & 21 & $162(1-76)$ & 7,7 & $1,21(1,0-3,5)$ \\
julho & 35 & $72(4-39)$ & 2,1 & $1,26(1,0-3,5)$ \\
agosto & 45 & $390(1-68)$ & 8,6 & $1,28(0,0-2,5)$ \\
setembro & 27 & $253(5-90)$ & 9,4 & $1,48(1,0-2,5)$ \\
outubro & 33 & $341(2-75)$ & 10,3 & $1,59(1,0-2,5)$ \\
novembro & 28 & $199(1-62)$ & 7,1 & $1,59(1,0-3,5)$ \\
dezembro & 36 & $247(1-45)$ & 6,8 & $1,58(1,0-3,0)$ \\
janeiro & 30 & $168(1-48)$ & 5,6 & $1,53(1,0-3,0)$ \\
fevereiro & 34 & $379(1-118)$ & 11,1 & $1,51(0,0-3,0)$ \\
março & 26 & $161(2-53)$ & 6,2 & $1,01(0,0-2,5)$ \\
abril & 29 & $45(3-11)$ & 11,3 & $\mathrm{~s} / 1$ \\
maio & 42 & $476(3-87)$ & & \\
\hline sion & & &
\end{tabular}

$\mathbf{s} / \mathbf{l}=$ sem leitura.

A chuva transporta os gases e partículas dissolvidos e em suspensão na atmosfera, bem como promove a lavagem do telhado. Esses dois eventos poderão depreciar a qualidade da água armazenada, portanto o correto manejo da água antes do armazenamento é fundamental para conservação dos padrões de qualidade exigidos para os diversos usos. Deverá ser feita a drenagem do excesso da água da chuva provocado por chuvas intensas e eliminação da água da chuva inicial que lava os telhados. No período inicial da chuva são carregados alguns detritos e contaminantes que ficam no telhado e calhas, assim alguns minutos de chuva farão a limpeza do telhado (Fendrich e Oliynik, 2002).

Os proprietários declararam que a água da primeira chuva era descartada, mas que em alguns momentos esse manejo não era feito. $O$ descarte era feito de forma manual, o que insere alto potencial de risco. Portanto, em certos momentos, a água da primeira chuva foi armazenada o que acarretaria impactos nas variáveis químicas e microbiológicas da água. $\mathrm{O}$ impacto do não descarte da primeira chuva será potencializado pela falta de limpeza da cisterna. Durante o período de monitoramento a cisterna não foi limpa, bem como o telhado e as calhas, portanto a matéria orgânica carreada pela chuva acumulou-se na cisterna. 
PALHARES, J. C. P.; GUIDONI, A. L. Qualidade da água de chuva armazenada em cisterna utilizada na dessedentação de suínos e bovinos de corte. Ambi-Agua, Taubaté, v. 7, n. 1, p. 244-254, 2012. (http://dx.doi.org/10.4136/ambi-agua.822)

Observou-se diferença significativa entre as amostras coletadas na superfície e fundo da cisterna somente para as variáveis de oxigênio dissolvido e temperatura (Tabela 2). Baixas concentrações de oxigênio no fundo da cisterna estão relacionadas a ausência de troca gasosa nesta região, pois na superfície há troca entre esta e a coluna de ar. As baixas concentrações também podem ser produto do acúmulo de matéria orgânica no fundo da cisterna o que provoca a consumo do gás na sua degradação aeróbia.

Tabela 2. Médias e erros-padrão das variáveis de qualidade da água na cisterna.

\begin{tabular}{|c|c|c|c|c|}
\hline \multirow{3}{*}{ Variáveis } & \multicolumn{4}{|c|}{ Profundidade } \\
\hline & \multicolumn{2}{|c|}{ Médias sem Correção ${ }^{1}$} & \multicolumn{2}{|c|}{ Médias com Correção $^{2}$} \\
\hline & Superfície & Fundo & Superfície & Fundo \\
\hline Oxigênio Dissolvido $\left(\mathrm{mg} . \mathrm{L}^{-1}\right)$ & $3,2 \pm 0,28 \mathrm{a}$ & $1,6 \pm 0,30 \mathrm{~b}$ & $3,4 \pm 0,27 \mathrm{a}$ & $1,7 \pm 0,28 b$ \\
\hline Temperatura $\left({ }^{\circ} \mathrm{C}\right)$ & $21,5 \pm 0,47 \mathrm{a}$ & $19,5 \pm 0,50 \mathrm{~b}$ & $21,6 \pm 0,83 \mathrm{a}$ & $19,3 \pm 0,87 \mathrm{~b}$ \\
\hline $\mathrm{pH}$ & $6,8 \pm 0,07 \mathrm{a}$ & $6,9 \pm 0,08 \mathrm{a}$ & $6,9 \pm 0,10 \mathrm{a}$ & $6,9 \pm 0,10 \mathrm{a}$ \\
\hline $\begin{array}{l}\text { Sólidos Dissolvidos Totais } \\
\left(\mathrm{mg} . \mathrm{L}^{-1}\right)\end{array}$ & $24,19 \pm 0,66 \mathrm{a}$ & $25,47 \pm 0,71 \mathrm{a}$ & $24,62 \pm 2,29 \mathrm{a}$ & $23,42 \pm 2,39 \mathrm{a}$ \\
\hline $\begin{array}{l}\text { Condutividade Elétrica } \\
\left(\mu \mathrm{S} . \mathrm{cm}^{-1}\right)\end{array}$ & $0,06 \pm 0,00 \mathrm{a}$ & $0,06 \pm 0,00 \mathrm{a}$ & $0,06 \pm 0,01 \mathrm{a}$ & $0,05 \pm 0,01 \mathrm{a}$ \\
\hline Potencial Redox (mV) & $-42,83 \pm 4,98 \mathrm{a}$ & $-52,25 \pm 5,36 \mathrm{a}$ & $-48,49 \pm 26,93 \mathrm{a}$ & $-45,25 \pm 28,13 \mathrm{a}$ \\
\hline $\begin{array}{l}\text { Coliformes Totais (UFC } 100 \\
\mathrm{~mL}^{-1} \text { ) }\end{array}$ & $659 \pm 189 \mathrm{a}$ & $947 \pm 189 \mathrm{a}$ & $653 \pm 309 a$ & $970 \pm 309 a$ \\
\hline $\begin{array}{l}\text { Coliformes Termotolerantes } \\
\text { (UFC } 100 \mathrm{~mL}^{-1} \text { ) }\end{array}$ & $632 \pm 187 \mathrm{a}$ & $932 \pm 187 \mathrm{a}$ & $624 \pm 302 \mathrm{a}$ & $958 \pm 302 \mathrm{a}$ \\
\hline $\begin{array}{l}\text { Escherichia coli } \\
\left(\text { UFC } 100 \mathrm{~mL}^{-1}\right)\end{array}$ & $27 \pm 10 \mathrm{a}$ & $21 \pm 10 \mathrm{a}$ & $29 \pm 14 \mathrm{a}$ & $18 \pm 14 \mathrm{a}$ \\
\hline Amônia (N-NH$\left.H_{3} \mathrm{mg} \cdot \mathrm{L}^{-1}\right)$ & $0,11 \pm \mathrm{a}$ & & $0,10 \pm 0,02 \mathrm{a}$ & \\
\hline Nitrito $\left(\mathrm{N}-\mathrm{NO}_{2} \mathrm{mg} \cdot \mathrm{L}^{-1}\right)$ & $0,02 \pm \mathrm{a}$ & & $0,02 \pm 0,00 \mathrm{a}$ & \\
\hline Nitrato $\left(\mathrm{N}-\mathrm{NO}_{3} \mathrm{mg} . \mathrm{L}^{-1}\right)$ & $1,18 \pm \mathrm{a}$ & & $1,18 \pm 0,07 \mathrm{a}$ & \\
\hline
\end{tabular}

1 médias sem correção para as variáveis de quantidade de chuva e velocidade do vento.

2 médias com correção para as variáveis de quantidade de chuva e velocidade do vento.

Médias seguidas por letras distintas, nas linhas, diferem significativamente pelo Teste $\mathrm{F}(\mathrm{p}<0,05)$.

O padrão de consumo para concentração de oxigênio estipulado pela Resolução $\mathrm{n}^{0} .357$ para águas Classe 3 é não inferior a $4,0 \mathrm{mg} . \mathrm{L}^{-1}$. Durante todo monitoramento, somente em quatro meses a concentração na superfície esteve de acordo com esse padrão. No fundo isso ocorreu apenas em uma coleta. Concentrações mínimas de $2,0 \mathrm{mg} . \mathrm{L}^{-1}$ e $0,3 \mathrm{mg} . \mathrm{L}^{-1}$ foram observadas na superfície e fundo, respectivamente. Apesar dessa realidade não foi detectado nenhum impacto negativo no desempenho zootécnico dos animais.

A temperatura da água apresentou média de $20,5{ }^{\circ} \mathrm{C}$, portanto em condições ideais para o consumo dos animais. As maiores temperaturas da água foram observadas entre os meses de novembro de 2009 e março de 2010 na superfície da cisterna, variando de $22,0^{\circ} \mathrm{C}$ a $26,6^{\circ} \mathrm{C}$, portanto mesmo no verão a cisterna demonstrou possuir a capacidade de manter a temperatura da água em valores satisfatórios para a dessedentação.

$\mathrm{O} \mathrm{pH}$ da água destinada ao consumo de animais pode variar de 6,0 a 9,0 (Brasil, 2005). Observou-se maior frequiência de valores básicos no fundo da cisterna, atingindo o máximo de 
PALHARES, J. C. P.; GUIDONI, A. L. Qualidade da água de chuva armazenada em cisterna utilizada na dessedentação de suínos e bovinos de corte. Ambi-Agua, Taubaté, v. 7, n. 1, p. 244-254, 2012. (http://dx.doi.org/10.4136/ambi-agua.822)

7,6. Isso se deve a natureza ácida das águas pluviais, ressaltando que a entrada de água da chuva na cisterna ocorria pela superfície.

As concentrações de Sólidos Dissolvidos Totais (SDT) sempre estiveram abaixo do padrão da Resolução que é $500 \mathrm{mg} . \mathrm{L}^{-1}$. A concentração máxima $\left(84 \mathrm{mg} . \mathrm{L}^{-1}\right)$ ocorreu em dezembro de 2008 na superfície da cisterna. No período entre essa coleta e a anterior observou-se uma das menores quantidades de chuva $(60 \mathrm{~mm})$ e a média de velocidade do vento foi a mais alta do estudo $(1,70 \mathrm{~m} / \mathrm{s})$. A concentração de SDT é um indicador importante, pois esses são potenciais carreadores de elementos poluentes que possuam características hidrofóbicas. As baixas concentrações de SDT demonstram que apesar do sistema de descarte da água da primeira chuva não ser o ideal, da proximidade da superfície de captação a uma rodovia com tráfego pesado e da presença de várias fontes emissoras de partículas no entrono, o sistema de filtragem se mostrou eficiente.

Altas correlações foram observadas entre a concentração de SDT e a velocidade do vento para ambas as profundidades (Figura 1). Isso atesta a influência do vento no transporte de partículas e o potencial impacto que esse transporte significa para conservação da qualidade da água armazenada. Em regiões agrícolas, como a desse estudo de caso, o uso de barreiras físicas (cercas vivas), a lavagem do telhado e o descarte das primeiras chuvas, devem ser práticas inerentes ao manejo da cisterna.

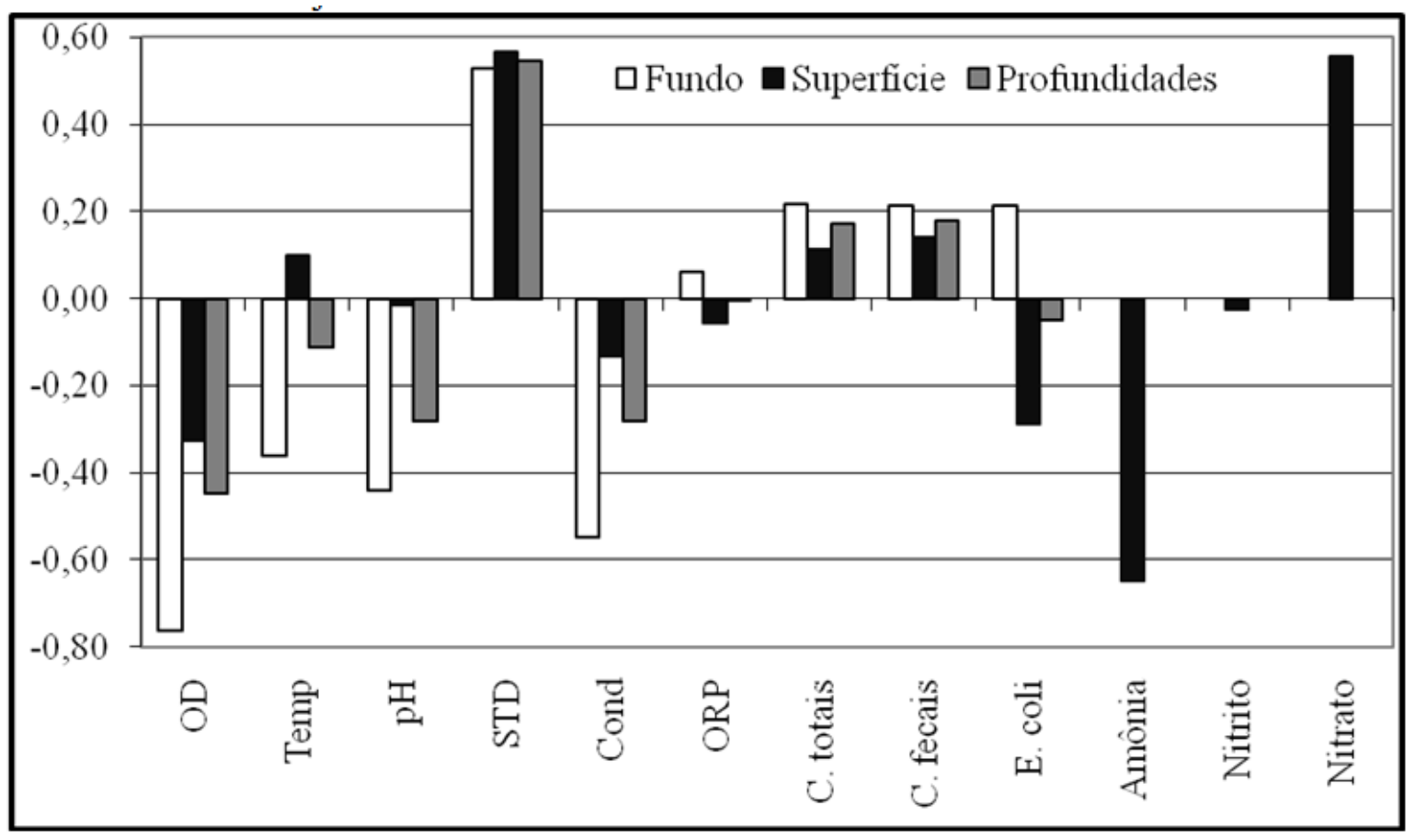

Figura 1. Correlação das variáveis de qualidade da água com a velocidade do vento.

Condutividade elétrica e potencial redox são duas variáveis que não apresentam padrão de qualidade para o consumo de animais. A Tabela 2 demonstra que não houve diferença significativa para ambas as variáveis entra as profundidades. Os baixos potenciais redox no fundo da cisterna são reflexo das baixas concentrações de oxigênio nessa profundidade.

Os padrões constantes na Resolução $\mathrm{n}^{0}$. 357 para amônia, nitrato e nitrito são respectivamente: 13,3 mg. $\mathrm{L}^{-1}, 10 \mathrm{mg} . \mathrm{L}^{-1}$ e 1,0 mg. $\mathrm{L}^{-1}$ (Brasil, 2005). Essas concentrações não foram atingidas em nenhuma das amostras coletadas, sendo as concentrações observadas muito baixas.

Entre os meses de fevereiro e maio de 2010 a amônia não foi detectada e as menores concentrações foram observadas entre outubro de 2009 e janeiro de 2010 . No caso da área de 
PALHARES, J. C. P.; GUIDONI, A. L. Qualidade da água de chuva armazenada em cisterna utilizada na dessedentação de suínos e bovinos de corte. Ambi-Agua, Taubaté, v. 7, n. 1, p. 244-254, 2012. (http://dx.doi.org/10.4136/ambi-agua.822)

estudo as principais áreas-fonte seriam as propriedades rurais devido a concentração de resíduos animais na forma de dejetos de suínos e camas de aviário. No período em que a amônia não foi detectada observou-se menores médias de velocidade do evento, portanto não foi verificada correlação entre as duas variáveis. Também foi baixa a correlação entre a concentração de amônia e a quantidade de chuva (Figura 2).

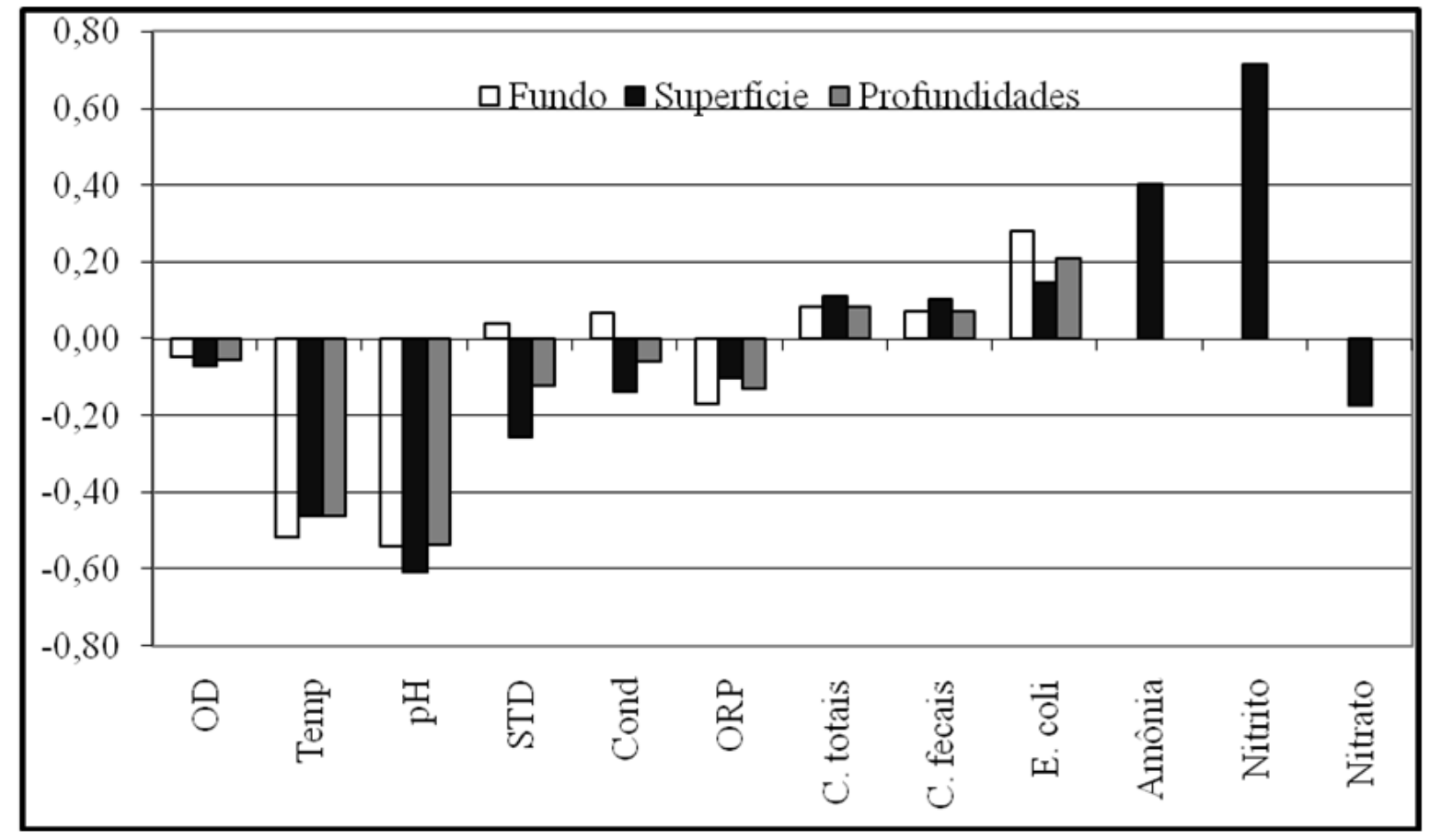

Figura 2. Correlação das variáveis de qualidade da água com a quantidade de chuva.

As mais altas concentrações de nitrato foram observadas entre junho e setembro de 2009, meses em que a movimentação do solo na região é intensa devido ao preparo deste para o plantio do milho. O nitrato apresentou alta correlação com a velocidade do vento (Figura 1). Os resultados demonstram que em propriedades ou regiões nas quais se pretende implantar cisternas o manejo do solo para o plantio e colheita das culturas agrícolas deve ser feito, considerando seu potencial impacto na qualidade da água armazenada. As menores concentrações de nitrato ocorreram entre janeiro e maio de 2010. Neste período se teve o maior acumulado de chuva e menores médias de velocidade do vento. Isso demonstra o poder de diluição que a chuva tem sobre a concentração do elemento.

Conforme a Resolução $n^{\circ} .357$ para dessedentação de animais confinados não deverá ser excedido o número de 1.000 Coliformes termotolerantes por $100 \mathrm{~mL}^{-1}$ em $80 \%$ ou mais de pelo menos seis amostras, coletadas durante o período de um ano, com frequência bimestral. Durante o monitoramento esse número só foi excedido em quatro amostras da superfície $(21 \%)$ e três amostras de fundo (16\%). Portanto, a água apresentou qualidade microbiológica para o consumo de animais.

Na cisterna monitorada os coliformes totais foram detectados em $79 \%$ (superfície) e $89 \%$ (fundo) e a $E$. coli em $26 \%$ (superfície) e $11 \%$ (fundo). Essas presenças não apresentaram um padrão identificado com as condições climáticas ou de manejo.

Segundo Schets et al. (2010), presença elevada de E. coli foi detectada em cisternas que tiveram suas águas amostradas em dias precedidos por chuvas intensas. Correlações de moderada a alta foram observadas entre a intensidade da chuva e a contagem de microrganismos. Esse tipo de correlação na foi observada neste estudo para a presença de $E$. coli. 
PALHARES, J. C. P.; GUIDONI, A. L. Qualidade da água de chuva armazenada em cisterna utilizada na dessedentação de suínos e bovinos de corte. Ambi-Agua, Taubaté, v. 7, n. 1, p. 244-254, 2012. (http://dx.doi.org/10.4136/ambi-agua.822)

Em janeiro de 2010, amostras de água dos três filtros foram coletadas. As análises demonstraram a presença de $E$. coli nos três filtros, sendo a concentração mais elevada no primeiro 700 UFC $100 \mathrm{~mL}^{-1}$ e no último $600 \mathrm{UFC} 100 \mathrm{~mL}^{-1}$. Esses resultados corroboram a teoria de que o sistema de filtragem compreendia uma fonte de contaminação para água da cisterna devido ao seu dimensionamento que possibilitava o acúmulo de água no fundo de cada um dos três filtros. Acredita-se que essa água foi carreada para dentro da cisterna, provavelmente devido a chuvas intensas e ao não descarte das primeiras chuvas, contaminando a água.

\section{CONCLUSÃO}

A água armazenada na cisterna apresentou qualidade satisfatória para o uso na dessedentação de animais de produção.

A presença de E. coli em algumas amostras esteve relacionada ao incorreto manejo da cisterna, estando estas ausentes na maior parte das coletas, conclui-se que a tecnologia apresenta viabilidade para o uso proposto desde que as boas práticas de manejo, as fontes de emissão do entorno e as condições climáticas sejam consideradas.

A quantidade de chuva e velocidade do vento influenciaram as concentrações dos elementos nitrogenados. Investigações a fim de aprofundar esse conhecimento devem ser conduzidas para que as fontes emissoras agrícolas e pecuárias não representam alto impacto negativo para a qualidade da água.

\section{REFERÊNCIAS}

AGRIOS, G. N. Plant pathology. San Diego: Academic Press, 1997.

\section{AMERICAN PUBLIC HEALTH ASSOCIATION. Standard methods for the examination of water and wastewater. Washington, 1995.}

ASSOCIAÇÃO BRASILEIRA DE NORMAS TÉCNICAS. NBR 15257: água da chuva aproveitamento de coberturas em áreas urbanas para fins não potáveis: requisitos. Rio de Janeiro, 2007. 8 p.

BRASIL. Conselho Nacional do Meio Ambiente. Resolução no $\mathbf{n}^{\mathbf{0}} 357$ de 17 de março de 2005. Dispõe sobre a classificação dos corpos de água e diretrizes ambientais para o seu enquadramento, bem como estabelece as condições e padrões de lançamento de efluentes, e dá outras providências. Disponível em: <http://www.mma.gov.br/ port/conama/legiabre.cfm?codlegi=459>. Acesso em: 8 fev. 2010.

BRASIL. Conselho Nacional do Meio Ambiente. Resolução nº 396 de 03 de abril de 2008. Dispõe sobre a classificação e diretrizes ambientais para o enquadramento das águas subterrâneas e dá outras providências. Disponível em: < http://www.mma.gov.br/ port/conama/legiabre.cfm?codlegi=562>. Acesso em: 12 abr. 2012.

BRITO, L. T. L.; GNADLINGER, J. Relatório sobre a oficina: avanços nos estudos sobre cisternas: qualidade de água e cisterna de alambrado. Petrolina: ABCMAC, 2006.

EVANS, C. A.; COOMBES, R. H.; DUNSTAM, R. H.; HARRISON, T. Identifying the major influences on the microbial composition of roof harvested rainwater and the implications for water quality. Water Science and Technology. v. 55, p. 245-253, 2007. http://dx.doi.org/10.2166/wst.2007.115 
PALHARES, J. C. P.; GUIDONI, A. L. Qualidade da água de chuva armazenada em cisterna utilizada na dessedentação de suínos e bovinos de corte. Ambi-Agua, Taubaté, v. 7, n. 1, p. 244-254, 2012. (http://dx.doi.org/10.4136/ambi-agua.822)

FENDRICH, R.; OLIYNIK, R. Manual de utilização de águas pluviais (100 maneiras práticas). Curitiba: Chain, 2002.

LYE, D. J. Rooftop runoff as a source of contamination: a review. Science of the Total Environment, v. 407, p. 5429-5434, 2009. http://dx.doi.org/10.1016/j.scitotenv.2009.07.011

MANTOVAN, P.; PASTOREA, A.; SZPYRKOWICZ, L.; ZILIO-GRANDI, F. Characterization of rainwater quality from the Venice region network using multiway data analysis. Science of the Total Environment, v. 164, p. 27-43, 1995. http://dx.doi.org/10.1016/0048-9697(95)04432-Z

NGIGI, S. What is the limit of up-scaling rainwater harvesting in a river basin? Physics and Chemistry of the Earth, v. 28, p. 944-956, 2003.

PRADO, G. S.; MULLER, M.S. K. Sistema de aproveitamento de água para edifícios. Revista Téchne, São Paulo, p. 77-80, 2007. Disponível em: <http://www.revistatechne. com.br/engenharia-civil/128/artigo66612-4.asp>. Acesso em: 22 jun. 2008.

SAS INSTITUTE INC. System for microsoft windows: release 9.1. Cary, 2003.

SAZAKLIA, E.; ALEXOPOULOSB, A.; LEOTSINIDISA, M. Rainwater harvesting, quality assessment and utilization in Kefalonia Island, Greece. Water Research, v. 41, p. 2039-2047, 2007. http://dx.doi.org/10.1016/j.watres.2007.01.037

SCHETS, F. M.; ITALIAANDER, R.; VAN DEN BERG, H. H. J. L.; RODA, A. M. H. de. Rainwater harvesting: quality assessment and utilization in The Netherlands. Journal Water and Health, v. 8, p. 224-235, 2010. http://dx.doi.org/10.2166/wh.2009.037

SIMMONS, G.; HOPE, V.; LEWIS, G.; WHITMORE, J.; GAO, W. Contamination of potable roof collected rainwater in Auckland. New Zealand. Water Resource, v. 35, p. 1518-1524, 2001.

WORLD HEALTH ORGANIZATION. Guidelines for drinking-water quality: recommendations. 3. ed. 2008. Vol 1. Disponível em: <http://www.who.int/ water_sanitation_health/dwq/gdwq3rev/en/>. Acesso em: 11 abril 2012. 